\title{
South African Public Libraries after Apartheid Robin Illsley
}

\begin{abstract}
One of the challenges a postcolonial society has to face is reconciliation, the righting of wrongs and forgiveness. In South Africa, this includes the integration of all ethnic groups into every part of society. Public libraries are one such part of society. This paper studies the changes that have been going on in South African public libraries since the end of Apartheid. The paper also explores how public libraries can play a role in the preservation of all South African cultures, with a view to the future and the essential role of public libraries in post-Apartheid society.
\end{abstract}

\footnotetext{
About the Author(s): Robin Illsley is currently a graduate student in Dalhousie University's MLIS programme. She received her Bachelor of Arts degree from Saint Mary's University in May 2005, with a double major in English and Anthropology. During her bachelor degree, Robin was introduced to, and became interested in, postcolonial studies. This paper was originally written for the class LIBS 5500, Information in Society.
} 


\section{Introduction}

All public libraries face challenges at one time or another. In the case of public libraries in South Africa, a unique challenge has had to be dealt with: overcoming the inequalities in service and collections after the end of Apartheid. For most of their history, public libraries in South Africa were created for, and used by, a white minority. Most of the materials in the libraries were in the two official languages, English and Afrikaans. This bias in acquisitions has had lasting effects on South Africans' perception of public libraries, and in the collections that those libraries contain. In 1993, as the racist Apartheid regime was nearing its end, nine other indigenous languages became official. The inclusion of resources in indigenous languages in South African public libraries is an essential step in reconciliation and cultural preservation.

After a brief overview of the history of South African public libraries, the current state of the public libraries will be discussed. Relevant questions the public libraries need to consider will then be posed and explored. Interlibrary loans, literacy, and a shortage of school libraries will also be looked at, to demonstrate the internal and external issues that are affecting South African public libraries. The paper finishes with a discussion of the potential public libraries have for language and cultural preservation, followed by the conclusion and areas of future research.

\section{Overview of the history of South African public libraries}

A brief overview of public libraries in South Africa is necessary for an understanding of the current problems. In 1928 the Carnegie Corporation of New York sent two librarians to South Africa to survey the library resources of the country. There had been a few attempts at developing small libraries for the black population, but most library development focused on white communities. One of the recommendations that came out of the Carnegie Commission's survey was that all library services should be available to the black, coloured, and Indian populations (Taylor, 1967). According to Irene Owens (2002), the Carnegie Corporation "regarded a library as a way to promote racial uplift, foster interracial understanding, and maintain social order" (p. 54). The Carnegie Corporation also gave grants to initiate these services, which began in the late 1930s. There is no indication, however, that these small collections contained any amount of material in indigenous languages.

These efforts at servicing the entire population were a positive step, but were not long-lasting. Bertha Mostert (1999) explains further: "Although several service points were in operation countrywide for the 'non-white' race groups, services for the black population fell into total disarray due to the lack of financial support when they were transferred from the provincial councils to the Department of Native Affairs in 1954" (p. 19). It was not until 1974, in Johannesburg, that a public library was open to all ethnicities in South Africa. This was an encouraging development, but there were still many problems to overcome. 
By the time public libraries were open to all people in South Africa, the library collections were quite well established in English and Afrikaans materials. These materials clearly no longer reflected the needs of the community being served. Mostert (1999) highlights one outcome: "In reaction to the unequal distribution of information sources, alternative information services were established in an effort to empower and bring the necessary information sources and services to the disadvantaged groups in society" (p. 20). What developed were community libraries and resource centers. These alternative services differed from public libraries, from the beginning. They had a pro-active approach to service and the types of materials they acquired were in any useful format, not necessarily print (Mostert, 1999). The less-educated population is better served by varied materials that do not depend on the borrower being literate. These alternative services were a reaction to the passivity of public libraries.

Disadvantaged people need someone to show them what information is available, to show them how to let go of limitations, and embrace the right to relevant information. A pro-active approach is especially important in a political climate like South Africa, where for many years a large group of people were denied information. Since the end of Apartheid, there have been progressive steps in equalizing service and in evaluating library services.

\section{Current state of South African public libraries}

The evaluation of public libraries is ongoing. Karin de Jager and Mary Nassimbeni (2005) write, "The National Library of South Africa has started to distribute the questionnaires to libraries throughout the country" (p. 43). These questionnaires, called the "Annual Public Library Statistical Report: Core Measures," will attempt to measure exactly how many resources each library has in each official language and what amount of their yearly budget was spent on these purchases. Although the Report does not address the current needs of the community it will be an undeniable indicator of what measures need to be taken next to better serve the community.

The current state of indigenous language resources in public libraries is quite poor. In a 2003 study, Fredericks and Mvunelo found that:

books in indigenous languages made up less than $1 \%$ of the collections of most responding libraries" (p. 139). There can be no real progress until the government aids authors, publishers, and libraries with increased funding for indigenous language material. To initiate positive change, "authors and publishers should be encouraged to produce more books in indigenous languages by promoting the languages at all levels of education, setting up government subsidized publishing houses and facilitating the marketing and use of the languages. (Fredericks \& Mvunelo, 2003, p. 139)

English and Afrikaans hold a privileged place in the South African public libraries, and this needs to be changed so that each official language has an important role in the libraries. The 
issues raised about support for indigenous language materials in this section will be further developed later in the paper.

\section{Issues to be faced}

Questions arise about South Africans' library needs. In South African communities, is there a demand for indigenous language materials? If not, is it still the responsibility of the library to provide the option of accessing materials in all 11 official languages? And finally, what is the current state of collections with regard to indigenous languages? All these questions are important to the future of South African public libraries.

\section{Reader demand}

The current demand for resources in indigenous languages is not very high in South Africa. One reason may be that "the reception of this literature has been influenced for years by corrupt and morally bankrupt publishing for schools" (Fredericks \& Mvunelo, 2003, p. 135). Originally, indigenous African language publications were published to promote certain ideas and values. For example, Christian societies wanted their message to reach all Africans, so using the indigenous languages was the only way to communicate with many of them. Another constraint was that:

The only viable market for books in the vernacular was the educational market, and as a result the only books published in the vernacular tend to be didactic and to lack originality. The majority of books that are made available in South Africa for all cultural groups, in the bookshops, schools and libraries, were selected and published by whites. (Fredericks \& Mvunelo, 2003, p. 134

This point of view can be disheartening. The majority of books may have been selected by whites, but this does not mean that they are only accessible by whites, or that white people do not include in their selections works that will be relevant to the entire population.

A contrasting, more positive, view about the selection process is given by Owens. For selections after 1994:

In terms of the representations of Africans in the book and reading culture, progress has been made and is still ongoing. The selection policy in terms of progress has been one of redress, not only in terms of supplying books to the deprived, but also in terms of trying to choose books that are relevant to the lives of black children. Selectors have tried to move away from the Eurocentric books often found in South African schools. They have sought out books with black characters and local settings. (2002, p. 57-58).

In Owens' view, there has been notable progress in some areas of selection. She does not mention, though, if any of the books being selected are in indigenous languages. Fredericks and Mvunelo (2003) go on to state: "Many of these books that were selected for the black 
community libraries and schools are totally unsuitable, because the values and attitudes reflected in them are those of white selectors rather than those of children for whom the books are intended" (p. 134). Are the values of white selectors really so different from those of a black selector? No one will be satisfied with a library's selections if one believes in such a dichotomy. However, the books selected during Apartheid are still sitting on the shelves of libraries and it is true that many of these are not relevant to today's library clients. The library has a certain responsibility to provide its clients with materials they will use.

\section{Library responsibility}

The South African Constitution states, "everyone has the right to use the language and to participate in the cultural life of their choice" (qtd. in Fredericks \& Mvunelo, 2003, p. 137). This choice cannot happen if an individual is not able to access adequate, current information in the language of his or her choice. The government should be at least partially responsible for ensuring its citizens' rights of language and choice as stated in the Constitution. It remains a fact that "English and Afrikaans, the home languages respectively of $8.68 \%$ and $15.66 \%$ of the population" (Nassimbeni, 1995, p. 290) dominate the information society in South Africa.

A major problem is that the libraries in Fredericks and Mvunelo's study did not have any written policies on the collection of indigenous language materials. Fredericks and Mvunelo (2003) believe that this suggests: "that these libraries do not regard it as a policy issue or service goal deserving serious attention. In other words...these public libraries do not seem to be making serious efforts to cater for the reading needs of members of their communities who are only literate in, or want to read books in, indigenous languages" (p. 138). The libraries counter this by reasoning that there is not enough interest in indigenous language material and few books are published in these languages (Fredericks \& Mvunelo, 2003). So, the publishers do not publish because there is no interest and the libraries cannot acquire the books because the publishers do not offer enough of them. If no one takes the initiative in supplying indigenous language materials it seems that nothing will change.

If resources in indigenous languages are important why are not more authors taking charge and writing for their communities? The problem lies in three main areas: "[l]nadequate public interest in books written in indigenous languages, insufficient income from writing books to make it a full time occupation, and lack of government support" (Fredericks \& Mvunelo, 2003, p. 136). With an increase in effective marketing public interest would also likely increase. South African writers may have to help change the public's perception of literature in indigenous languages; they have to make it known that writing in African languages is just as relevant and worthy as writing in English or Afrikaans. Authors need the help of government and publishers in this endeavor.

Should the library supply its clients with a selection of indigenous language materials if there is no perceived interest? Perhaps that is the role of another institution, maybe the National 
Library of South Africa. However, even the National Library has its critics. Gabrielle Ritchie and Mandla Hermanus (2004) challenge the idea that the National Library is neutral territory:

The content of the National Library's collections necessarily influence what is judged to be historically important. More specifically, it is the way that these collections are managed, profiled, promoted and researched that elucidates what is judged to be significant as South African history. (p. 3)

It is the duty of the public library to provide neutral access to information for its clients. If the public libraries conducted a community wide survey of the interests of information seekers, instead of judging by what people who already use the library want, they might discover that there is a greater interest in indigenous language reading material than they expect. It is the library's responsibility, mission even, to serve the community to the best of its ability even if it means being more pro-active than in the past. Having materials in indigenous languages available in public libraries may validate the native languages of many Africans and create a greater demand for such resources. This endeavor to increase indigenous language resources will require support from other institutions but public libraries need to show initiative. There are also internal and external issues that South African public libraries have to consider in order to become more effective, such as interlibrary loans, literacy, and the shortage of school libraries.

\section{Interlibrary loans}

It is difficult to become information literate if one's access to information is limited. Interlibrary loans between South African libraries would seem to be one internal solution to limited resources. Interlibrary loans would also be useful in circulating scarce indigenous language materials. However, according to Jenny Raubenheimer (1998): "[Public and community] libraries make very little use of the interlending system, owing to a lack of funds and the inability of clients to meet costs" (p. 73). Costs is a major problem because it is causing clients to become unsatisfied with available resources. If neither libraries nor their clients can meet these costs, the government could provide some assistance.

\section{Literacy}

Literacy plays an important role in South African public libraries. Historically, a 1911 census "found that only 6.8 percent [of native Africans] could read or write" (Owens, 2002, p. 54). At that time, the main focus of libraries was on print material, most often in English or Afrikaans. Not only could most native South Africans not read the material available for reading was in a foreign language. Of the available books "few books were in African vernaculars, and even fewer written by Africans themselves to present a more balanced viewpoint" (Owens, 2002, p. 54). In addition, the government did not want the black population to become literate. Owens (2002) states: "The most important struggle concerned the use of reading as a route to selfawareness and self-advancement, which was not in agreement with the intent of the Bantu 
Education Act" (p. 55). When there is such powerful opposition to a goal, accomplishing it can seem impossible.

Public libraries in South Africa were "based on the Western library model, i.e. print-based and mostly for leisure purposes...[I]iteracy has thus always been a precondition for the use of these services" (Mostert, 1999, p. 20). South Africa is a case where the traditional library model does not fit with the current cultural context. The school age population in South Africa is one that is becoming increasingly literate and public libraries have to take this fact into account, and work on solutions that serve the needs and wants of the historically disadvantaged populations.

\section{Shortage of school libraries}

Another external challenge public libraries in South Africa are facing is the lack of school libraries. This lack places strain on the resources of public libraries. In fact, some librarians claim to feel victimized by recent educational changes. South Africa's 2001 Revised National Curriculum Statement states that one of its goals is to produce learners who "can gather, analyse, organise, evaluate \& communicate information" (Hart, 2004, p. 111). However, less than $30 \%$ of South African schools have adequate school libraries that allow learners to gain this attribute (Hart, 2004). Instead, students rely on public libraries. This has led to many complaints from public librarians. Some of the complaints are: "teachers do not come to the library; they do not inform the library of school projects in good time; and learners are not being taught how to use the library effectively" (2004, p. 114).

The last complaint voiced by the South African librarians is problematic. Should it not be their responsibility to teach students how to use the library effectively? It could be the case that many educators themselves do not have experience with public libraries, so teaching the effective use of the library rests with librarians (Hart, 2004, p. 113). Another road block is "there is no catalogue or database or subject index available for public use" (Hart, 2004, p. 118). Librarians take the students to the shelf area required (Hart, 2004). Students cannot learn to use the library independently when there are not enough tools available to help them. The National Curriculum Statement may state that it is trying to produce a certain type of learner, but the statement alone does not ensure that the goal is becoming a reality.

Educators do not recognize the stress they are putting on library resources and public libraries are not receiving any additional assistance from the government to support this increased usage. Hart (2004) notes: "As long as public libraries perform their educational role in ad hoc improvised ways, with no formal recognition of their work, they will remain victims" (p. 119). Librarians are not being vocal enough about their concerns. Hart (2004) advocates that libraries embrace their role in education, so that attention will shift "from how the curriculum has impacted on libraries towards how libraries are impacting on the curriculum" (p. 119). If South African school children are spending so much time in public libraries, and public libraries begin to promote their indigenous language materials, there could be a positive effect on both 
sides. The school children would be reinforcing their own native languages while increasing the interest in indigenous language materials allowing libraries to buy more materials from publishers.

Hart points out that the public library "is a creature of the $19^{\text {th }}$ century" (Hart, 2004, p. 112). As a result, it is not a service that directly relates to the unique situation of South Africa. Librarians cannot expect to be exempt from the society around them. If needs are not being met, librarians should change their policies to help the community they serve instead of relying on how things have been done in the past. In the case of South Africa " $t$ t] his might imply a shift towards playing a more active role in formal education rather than the traditionally indirect supportive role of the Western model" (Hart, 2004, p. 112). Interestingly, the "Western model" may not even fit with the "West" anymore. Librarianship everywhere is changing in our information society and each library needs to assess the community it serves individually and base its services upon that assessment. In South Africa, these needs are a place for language and cultural preservation.

\section{Language and cultural preservation}

Some might argue that it is too late to bring indigenous languages back into the social consciousness of South Africa. Most school children know English or Afrikaans and the indigenous cultures they come from are being lost. Information is kept and stored for preservation in an information society. If no books are written in indigenous languages, how will that language survive? Of course, there will be those who speak the language. But, languages are dying out fast in our global village where a common language is needed to communicate. This common language is not going to be an African language. This means, however unfair, that those who speak African languages must try harder to preserve their language. One way to do this is to publish books in indigenous languages. If these books are then stored in public libraries then the language has a better chance of survival.

Technologies may be available that will help develop indigenous South African languages more efficiently than a public library. Projects, like the African Speech Technology Project, demonstrate that the government is taking definite measures to promote and incorporate indigenous languages into South African culture. The government needs to become aware, however, of the potential role public libraries in this promotion. A study was conducted which tested the ability to search an English database in Zulu, the language spoken by the majority of South Africans. A problem they encountered was that "Zulu does not have single word translation equivalents for many technical and scientific terms" (Pirkola, Cosijn, Bothma \&amp; $\mathrm{Nel}, 2002$, par. 3.4). The solution was to either paraphrase or borrow words from another language (2002, par. 3.4). The purpose of this research was to assess the helpfulness of metadata in cross-lingual information retrieval and it generally proved to be useful. This study is a step in the right direction. Even if material is not available in an indigenous South African 
language a searcher would at least be able to find what information is available in the language of his or her choice.

\section{Conclusion}

Though advances in technology are being made, there is still the question of the availability of indigenous language materials in South African public libraries. Books still have a strong impact. Owens (2002) quotes a South African author who was greatly impacted by books: "I read all the books on the shelf marked: American Negro Literature. I became a Nationalist through the writings of men and woman who lived a world away from me. To them I owe a great deal for crystalizing my vague yearnings to write and for showing me the long dream was attainable" (Abrahams in Owens, p. 56). It is inspirational to see a representation of oneself. A South African child or teenager may aspire to be an author and there is no reason why he or she should have to write in English or Afrikaans just so the book will sell. If public libraries put more effort into developing indigenous language materials, publishers would be able to sell more books, and authors would be able to write more books.

There is also the element of reconciliation in the public libraries of South Africa. If clients go into the library and are confronted with only English and Afrikaans language materials, many of the clients will not feel that the library is an accurate representation of the current cultural reality. If nothing changes in the public library it is as if reconciliation is being ignored. The public library should be a place where no ethnic group feels either privileged or disadvantaged. It should be a neutral area to interact with other members of a diverse community and an area in which one can access information in the official language of one's choice. South African public libraries should also react to the need for cultural preservation. One of the most important aspects of culture is language, which is facing challenges in South Africa. By adding more indigenous language materials to their collections South African public libraries can play a key role in the cultural preservation of the entire nation.

\section{Future research}

There are multiple areas for future research in this subject area. Evaluating collections should occur in every library, but this evaluation is particularly important in postcolonial societies. How other postcolonial societies are coping with reconciliation and language and cultural preservation would help contextualize South Africa's position. In addition, research on how South African public libraries are progressing is needed. There is a potentially rich area of study in the selection of children's books in societies where people are trying to promote native authors and subject material. Finally, a look into the South African government's response to the needs of public library clients, and how the government can better serve its people through libraries, would be helpful in clarifying what role the government should play in supporting public libraries. 


\section{References}

Cosijn, E., Pirkola, A., Bothma, T., \& Nel, J.G. (2002). Cross-lingual information access in indigenous languages: a case study in Zulu. South African Journal of Library \& Information Science, 68(2), 94-104. Retrieved December 1, 2005 from Academic Search Premier database.

Fredericks, G.H. \& Mvunelo, Z. (2003). Publication of books in indigenous South African languages and their availability and use in public libraries. South African Journal of Library \& Information Science, 69(2), 133-139. Retrieved November 26, 2005 from Academic Search Premier database.

Hart, G. (2004). Public libraries in South Africa: Agents or victims of educational change? South African Journal of Library \& Information Science, 70(2), 110-120. Retrieved November 26, 2005 from Academic Search Premier database.

Jager, K. de \& Nassimbeni, M. (2005). Towards measuring the performance of public libraries in South Africa. South African Journal of Library \& Information Science, 71(1), 39-50. Retrieved November 26, 2005 from Academic Search Premier database.

Mostert, B. J. (1999). Information provision services in South Africa: a comparative study. Library Management, 20(1), 19-26. Retrieved November 26, 2005 from Emerald database.

Nassimbeni, M. (1995). Collection development in public libraries in South Africa: New library and language policies. Library Acquisitions: Practice \& Theory, 19(3), 289-297.

Owens, I. (2002). South African libraries from pre-Apartheid to Apartheid in the 1960s and 1970s: The beginning of the end. Library Management, 23(1/2), 53-58. Retrieved November 26, 2005 from Emerald database.

Raubenheimer, J. (1998). Interlibrary loans in new democratic societies: South African experiences. Interlending \& Document Supply, 26(2), 70-75. Retrieved November 26, 2005 from Emerald database.

Ritchie, G. \& Hermanus, M. (2004). Challenging 'neutrality': Investigating the National Library of South Africa. Retrieved December 1, 2005, from National Library of South Africa:

Publications web site: http://www.nlsa.ac.za/publications.html

Taylor, L. E. (1967). South African Libraries. London: Archon Books \& Clive Bingley. 